\title{
Assessment of the remains in historic urban area based on spatial prototype
}

\author{
Case study on Jingmen city, China
}

\author{
Guangtong XU, Huazhong University of Science and Technology, China \\ Yi HE, Huazhong University of Science and Technology, China
}

\begin{abstract}
Like most historic and cultural cities in China, the historic urban area of JingMen city is facing a typical spatial problem of fragmentation and fuzzification. This study is focused on exploring a method for evaluating the existing values of historic urban area based on spatial prototype. As a built-up relationship of historic city, spatial prototype has habitual structural characteristics and formal modulus. It is the inherent logic and order rules behind the scattered historic environment, providing a clue to understand the spatial characteristics and a basis for guiding the construction and conservation in historic urban areas. Three criteria, the resolution of historical elements, the integrity of historical structure and the renewal potential of associated plots, were selected to construct the assessment system. These three dimensions are linked to the spatial prototype and its constituent elements, as well as the transformation relationship in ancient and present day. The results showed that historic urban areas have changed from a holistic city to different existing types dominated by their historic structure elements. Finally, a constructive conservation strategy should be adopted to enhance the integrity of historic urban area based on the trace of spatial prototype and evaluation results.
\end{abstract}

\section{Keywords}

Constructive conservation, existing value, historic urban area, spatial prototype

\section{Introduction}

In China, the space of a historic city was an organism formed by the long-term interaction between the traditional urban construction mode and the local natural environment (Dong, W., 2019). However, after 1949, most cities had experienced regime change, traffic reform and rapid urbanization, especially during the past 20 years, the old urban areas were often regarded as the main object in the process of urban renewal (Lin, L., 2016). Now the historical built environment is facing a serious spatial problem of fragmentation and fuzzification. And the current conservation methods have encountered multiple dilemmas for few historical streets and buildings left. In a word, it is urgent to explore a new method to understand the value of a historic urban area and coordinate the relationship between conservation and development when we are faced with a complex heritage environment with many modern elements ( $\mathrm{He}$, Y., 2017). 
Urban space form, especially in historic city, has its habitual combination logic and plane order, from which a spatial prototype could be abstracted (Yang, J.Y., 2016). The prototypal analysis of a historic city's spatial structure is the core issue of heritage conservation at the urban level (Chang, Q., 2017). It can be said that spatial prototype is a kind of holistic logic under the scattered surface of space, which has been dominating the change of space and the replacement of elements, and is a basis for coordinating the relationship of conservation and development. Therefore, based on the conservation planning experience of Jingmen historical and cultural city, this paper reflected on the limitations of the current heritage protection knowledge and methods, learned the analysis method of prototype in architectural typology and tried to explore a kind of evaluation method and holistic conservation strategy of historic urban area from the overall level of an ancient city. It is of great significance to the conservation of historical and cultural cities in modern society.

\section{The proposal of the concept of ancient city's spatial prototype}

Prototype, with the literal meaning of an original normal form, is a concept originated in the field of psychology, referring to an accumulated experience structure or a repeated image (Zhang, L.H., 2016). In architecture, it is defined as a kind of enduring and similar spatial structure schema, which is a kind of logic and rule of space form-existing before a specific building and making up it (Huang, S.J., 2006), and the schema characteristics of architype could be grasped by the entity image and virtual image of the spatial elements (Liu, L.,2017). Moreover, the prototype analysis method has built a complete theoretical framework for the study of classification and design of building types and provided a set of systematic rules for the construction of regional cultural characteristics (Wang, L.J., 2019).
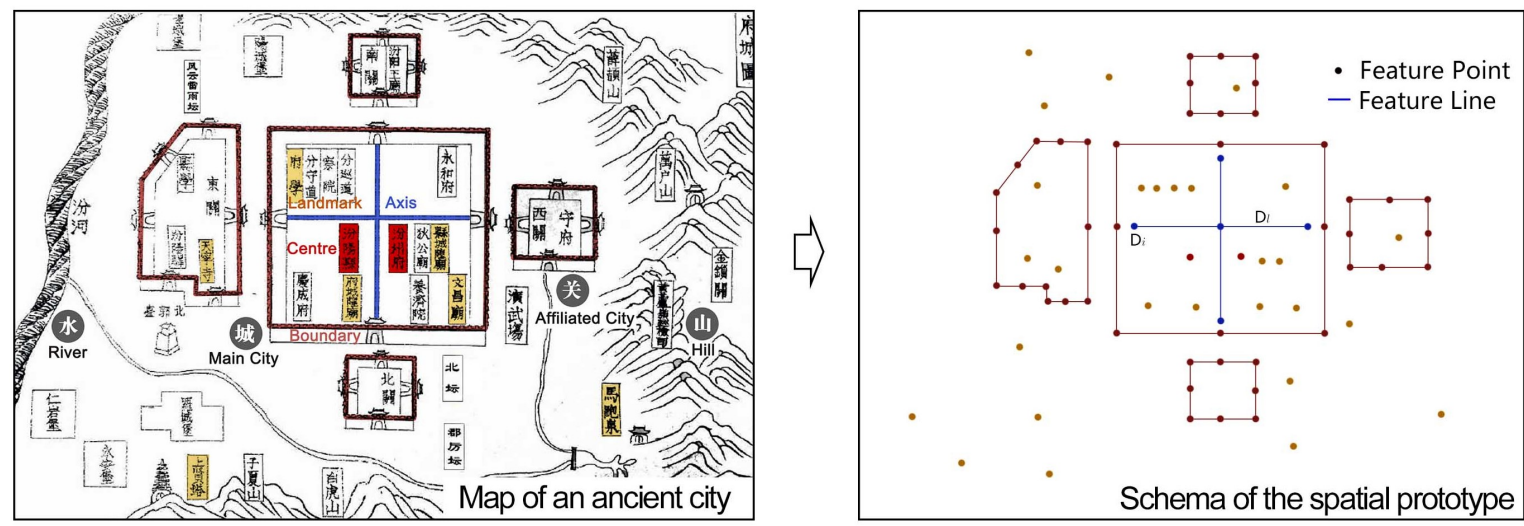

Figure 1. Illustration of the spatial prototype and its constituent elements. Source: the left one from the chronicle of Fenyang ancient city.

The space of historic city and traditional residential courtyard in China shares an isomorphic characteristic (Zhu, W.Y., 2011), reflecting the hierarchical order of certain powers. Urban morphology and architectural typology also have a complementary nature and an internal connection through the synchronic and diachronic of spatial elements (Shen, K.L., 2010). However, the significance of the research on prototype in the theory and practice of historic urban area has been rarely mentioned or discussed. In view of this, according to the definition of prototype, this article put forward the concept of spatial prototype of historic urban area and defined it as a common combination schema of specific spatial elements. As an overall and stable order rule, it is the internal logic that dominates the evolution of urban space. Under the unified regulation of Chinese traditional city management system, a schema composed of the historic center, boundary, axis and landmarks could be found in most historic cities' space, which has also become a holistic image and the collective memory of the ancient city. Therefore, this schema is defined to represent the spatial prototype of historic urban area (Figure 1). The spatial 
elements and their combination are important clues to understand the spatial characteristics of historic urban area.

\section{Assessment of the remains in JingMen historic urban area}

Before the assessment, it is necessary to have a brief understanding of the history and current situation of Jingmen ancient city. The city was located in the central part of Hubei Province, China, between Jingzhou ancient city in the south and Xiangyang ancient city in the north, being an important defensive stronghold in the area. Jing-xiang old road started from Xiangyang, passed through Jingmen old city and reached Jingzhou, which had been a very important national trade channel in ancient China (Yang, Z.T., 1994). The city began to be built in the Northern Song Dynasty (Ad 962), formed the framework of space in the Southern Song Dynasty (Ad 1191) and reached the completion state in the late Qing Dynasty (Lu, X.Q., 2011) (Figure 2). Nowadays, after repeated modern construction, most of the old city wall has been destroyed, only two city gates were left. Many historical buildings cannot be found inside the wall, but it is easy to identify the historic structure of the city on today's maps by comparing it with spatial prototype.
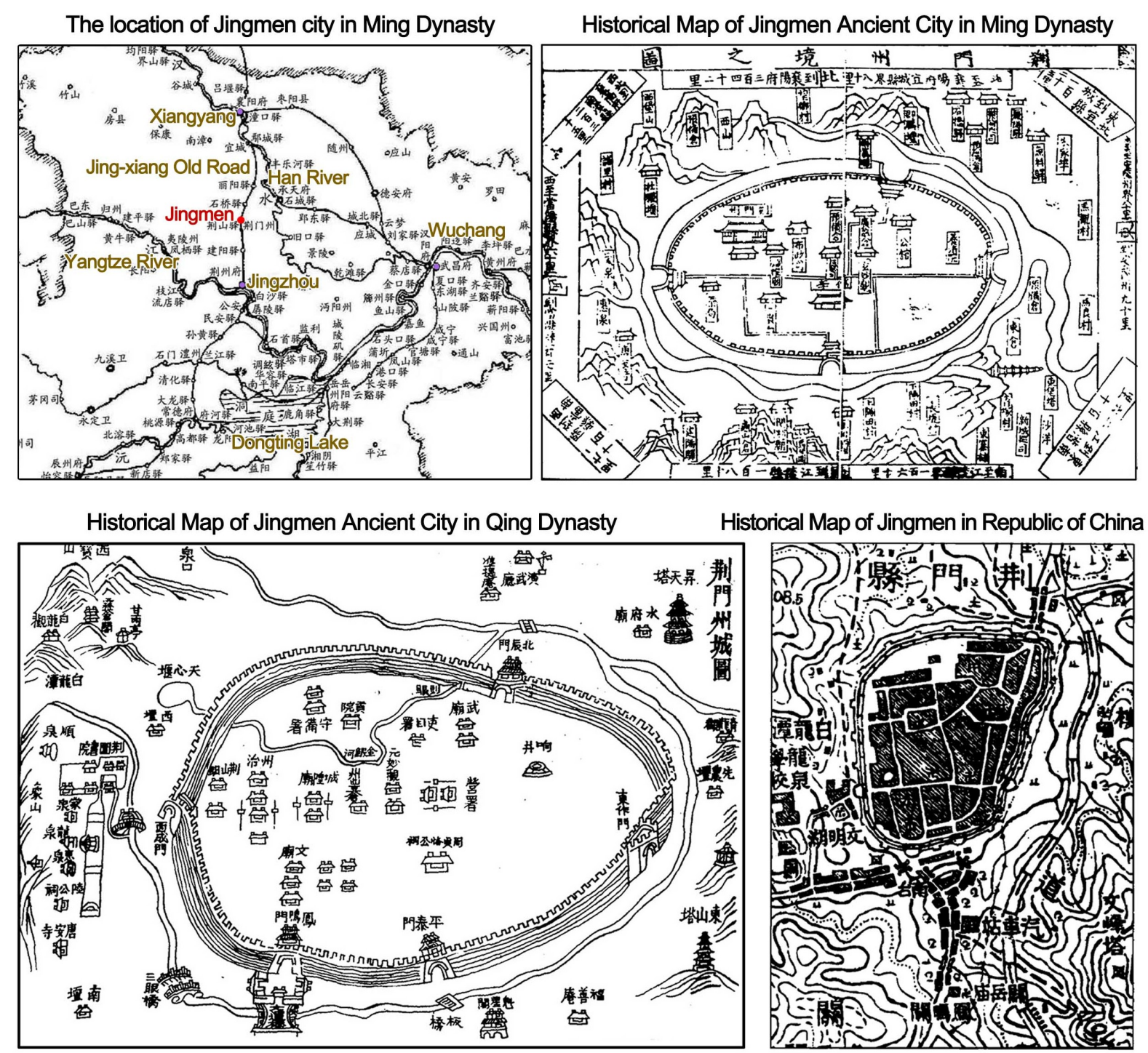

Figure 2. Historical maps of different periods of Jingmen ancient city. Source: Conversation plan for Jingmen historic and cultural city (2017-2030). 
Based on the comparison between initial and current state of the spatial prototype, three criteria, the resolution of historical elements, the integrity of historical structure and the renewal potential of associated plots, were selected to construct an assessment system to analyse the existing characteristics of the historic urban area.

\subsection{Resolution of historical elements}

After translating the past spatial information into today's map, two factors, physical visibility and psychological visibility, were chosen to evaluate the resolution of historical elements. The physical visibility was divided into five classes: well protected, reconstruction, replacement, identifiable and unidentifiable, based on the authenticity of certain spatial element, and the psychological visibility was mainly supported by residents' effective recognition of spatial elements' photos, those living inside the historic urban area (Table 1).

Table 1. Resolution assessment system of historical elements.

\begin{tabular}{|c|c|c|c|c|c|c|c|}
\hline \multicolumn{5}{|c|}{ Physical visibility } & \multicolumn{2}{|c|}{ Psychological visibility } & \multirow[t]{2}{*}{ Resolution } \\
\hline $\begin{array}{l}\text { Well } \\
\text { protected } \\
(100 \%)\end{array}$ & $\begin{array}{l}\text { Reconstruction } \\
(80 \%)\end{array}$ & $\begin{array}{l}\text { Replacement } \\
(50 \%)\end{array}$ & $\begin{array}{l}\text { Identifiable } \\
(30 \%)\end{array}$ & $\begin{array}{l}\text { Unidentifiable } \\
(0 \%)\end{array}$ & $\begin{array}{l}\text { Effective } \\
\text { recognition }\end{array}$ & $\begin{array}{l}\text { Total } \\
\text { number }\end{array}$ & \\
\hline & $80 \%$ & & & & $\mathrm{n}$ & $\sqrt{ }$ & $80 \%+(n / N)$ \\
\hline
\end{tabular}

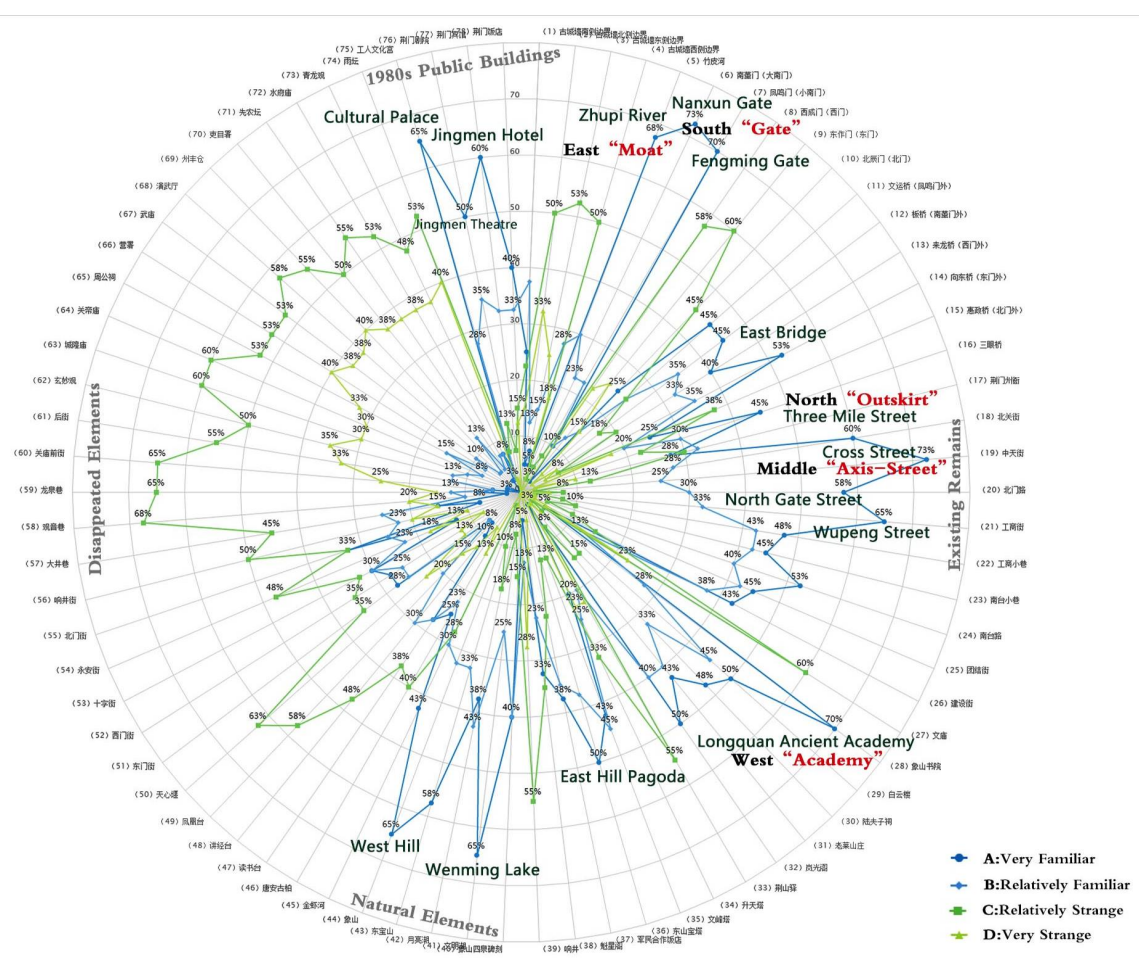

Figure 3. Psychological visibility of the spatial elements in Jingmen historic urban area.

Then, in the evaluation process, the physical visibility of every element was scored by the fieldwork directly, while the psychological visibility was got through questionnaires with pictures to survey local residents' perception of the elements, and 120 valid questionnaires were withdrawn (shown in Figure 3 ). The final results of resolution were visualized by ArcGIS (Figure 4), and the darker the color, the higher the resolution. As far as spatial distribution is concerned, the elements with high resolution are all located near the periphery of the historic city, mostly in the northeast and southwest. And for the categories of elements, the resolution of historic axis-street is much higher than others. In a word, spatial elements from different directions, Southern Gate, Northern Outskirt, Western Old Academy, Eastern 
Moat and Middle Axis-Street, represent a relational schema of Jingmen ancient city. In the future, conservation work should not only pay attention to the elements with high resolution, but also strengthen this image with the modern technology 、 public arts or landscapes.

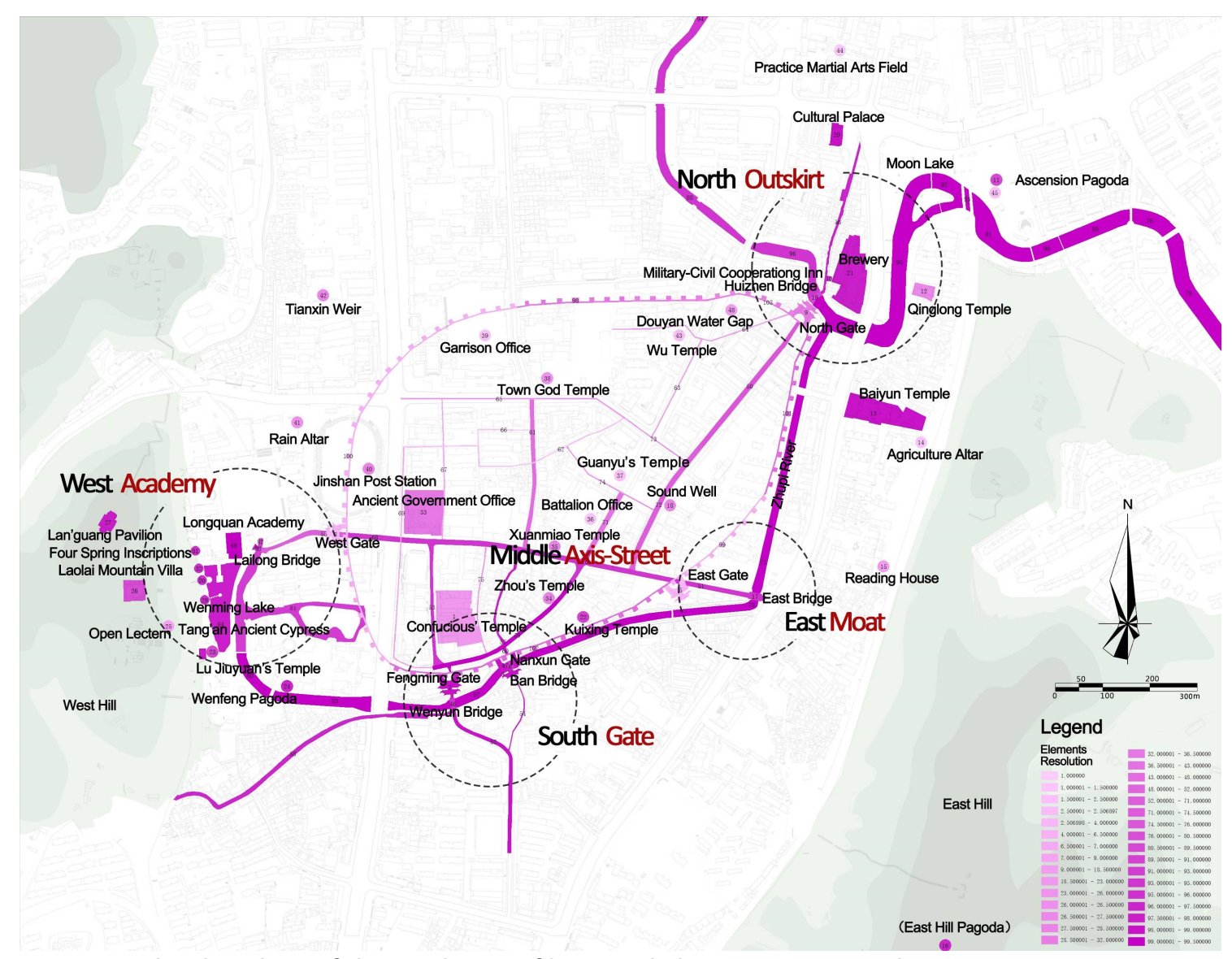

Figure 4. Visualized analysis of the resolution of historical elements in Jinmen historic city.

\subsection{Integrity of historical structure}

It is known that authenticity and integrity are the two important principles to evaluate the value of heritages, and different from the assessment of resolution above, which is aimed at the existing status of spatial elements based on authenticity, the integrity of historical structure is more based on the holistic pattern of spatial prototype to reveal the internal correlation among the separate spatial elements.

As a hub on an old road, Jingmen ancient city played an important role in military defence and commercial trade, so besides the natural environment, defence and trade systems could be two key clues to learn the spatial prototype and the overall characteristic of the historical structure. From the perspective of geographical landscape, the natural pattern was an internal and external double encirclement with two mountains confronting each other and three rivers meeting at a point, which was the initial structure for the city space expansion to follow. In term of defence, the city wall and gates, moat and suspension bridges, main street and lane, as well as ancient passes in different directions constituted a whole defence system. And according to the trade system, Jing-xiang old road passed through the city and connected two outskirt areas outside the south and north gate, forming a business zone with inner street and outer street connecting (Li, B.W., Wang, W. and Li, W.H., 2011) (Figure 5). According to this holistic pattern, the integrity of historical structure in historic urban area is determined by the four constituent elements of the spatial prototype, historic centre, boundary, axis and landmark. In this study, the integrity of these four elements was calculated respectively based on the resolution of their feature points and lines, and the final result of historic axis-street system was the highest, followed 
by the historic boundary, which suggested that the current spatial features were dominated by the linear spatial elements.

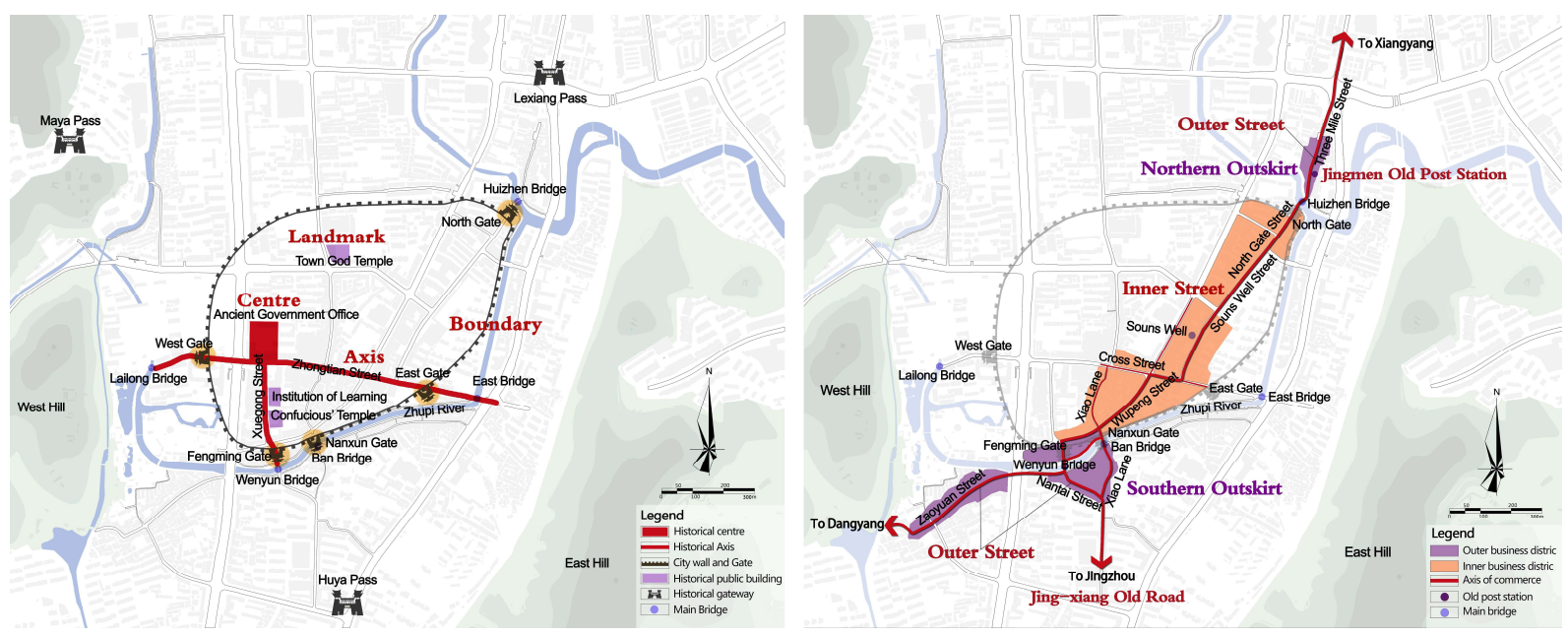

Figure 5. the spatial pattern of the defense and trade systems of Jingmen ancient city.

\subsection{Renewal potential of associated plots}

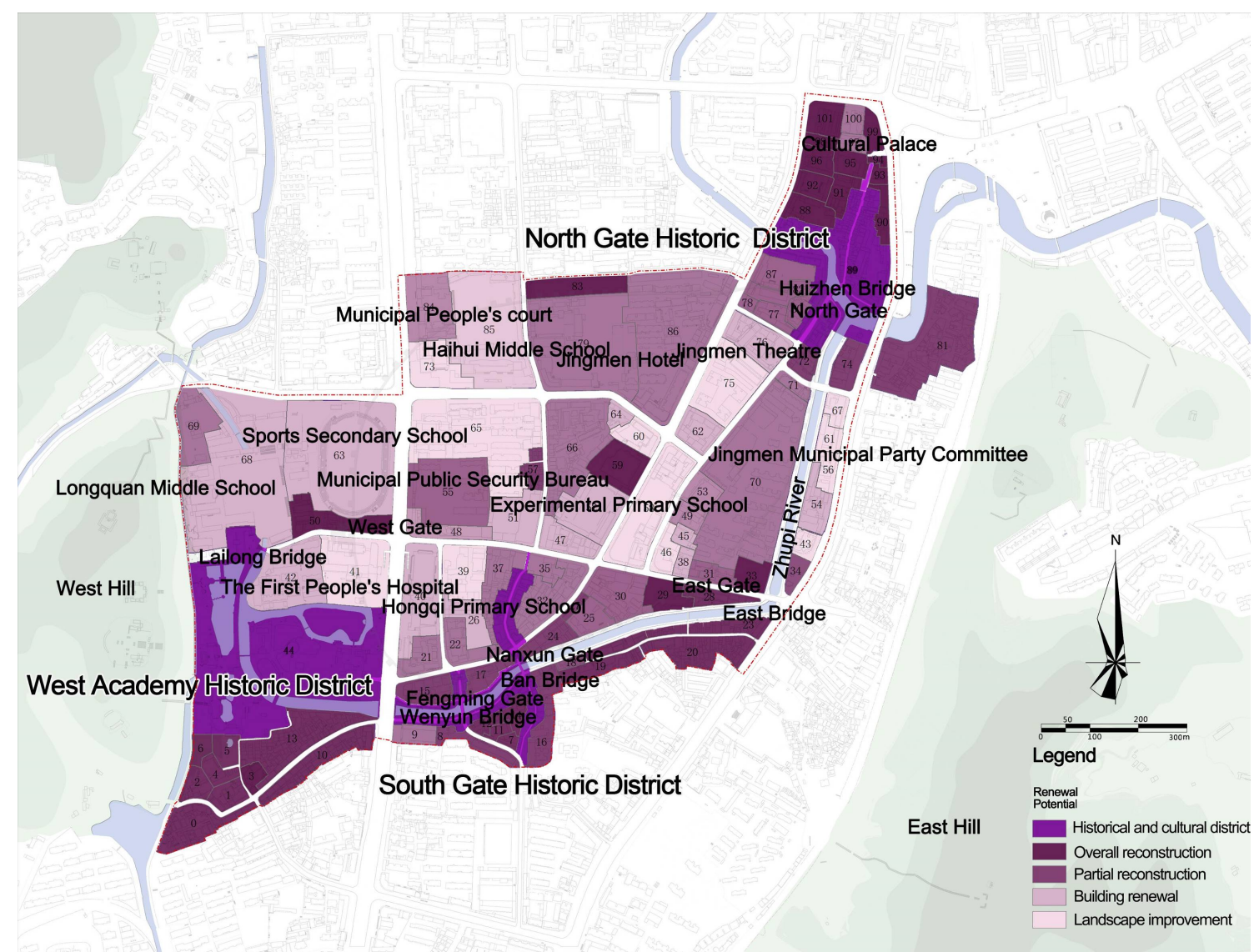

Figure 6. Assessment results of plots' renewal potential in Jingmen historic urban area.

To strengthen the connection of the constituent elements of prototype schema is based on the renewal potential of the associated plots, which will determine the feasibility of constructive conservation schemes for historic urban areas in the future. Except for three historical and cultural districts, the plot's renewal potential was classified into four levels: overall reconstruction, partial reconstruction, building renewal and landscape improvement, mainly according to the quality of the buildings within every plot. 
By analysing the current situation of each plot and the renewal plan from the government, the results of renewal potential were ascertained and show in Figure 6 . The plots with high renewal potential were mainly located inside and outside the ancient city gate and only a few of them scattered in the interior area. Since these plots will play a transitional and connecting role between the old blocks and the new blocks, they should be treated as special renewal areas during the process of urban development. In these plots, appropriate measures can be taken to reveal their historical information and improve the integrity of the structure of the historical built environment.

\section{Constructive conservation scheme for Jingmen historic urban area}

Traditional methods by delimiting conservation area are more oriented to protect the existing heritages and control their surrounding construction (Xu, G.T., 2020). However, we often encountered bottlenecks when we applied these methods to those cities like Jingmen, with few historical buildings but a holistic traditional street network. Therefore, under the framework of urban development, we need not only restoration work, but also much constructive work to connect the scattered historical space elements, improve the integrity of historical environment and reveal local historical and cultural information.

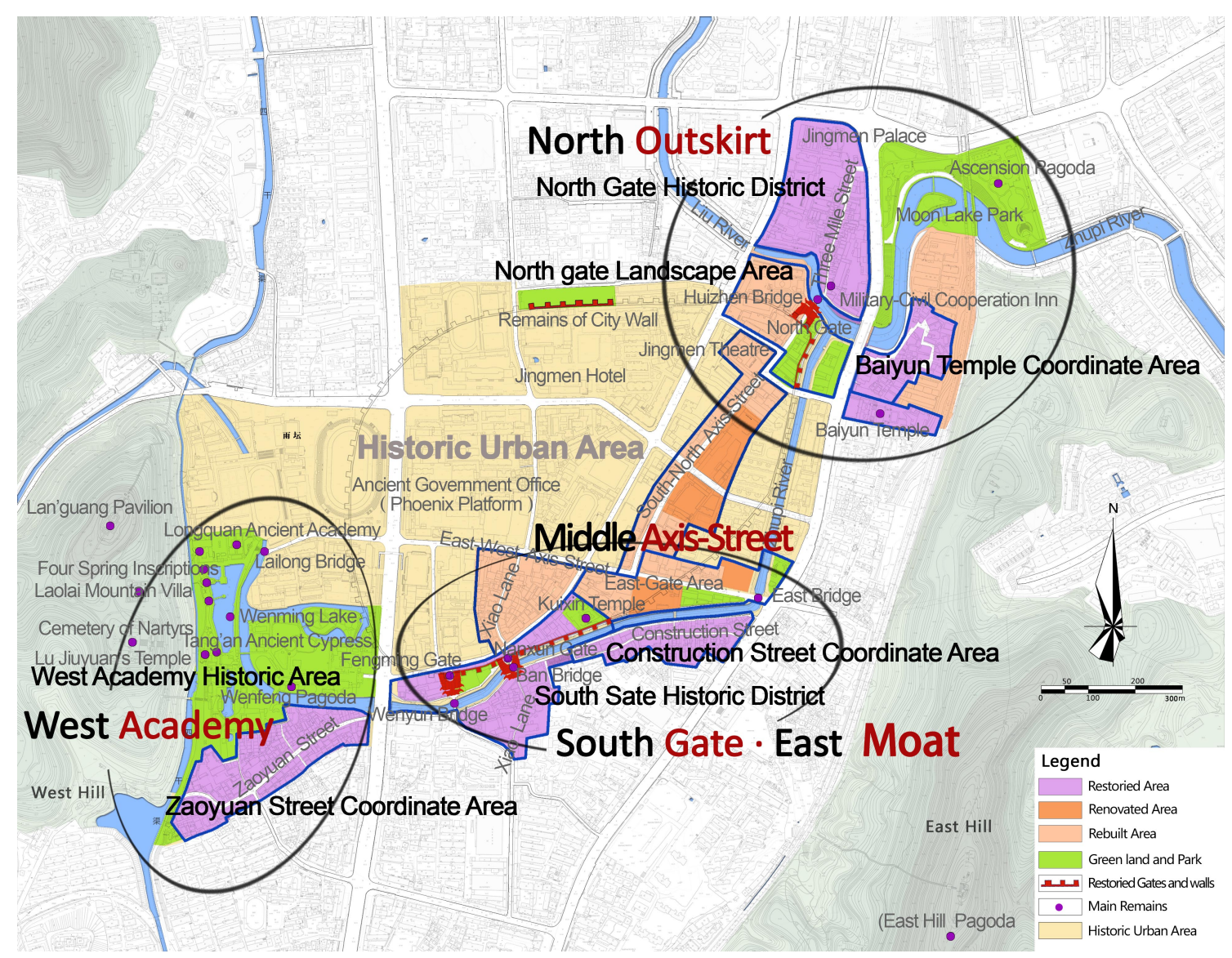

Figure 7. Constructive conservation scheme for Jingmen historic urban area.

According to the results of assessment above, we found, in a certain sense, that only half of the historic urban area is a relatively holistic historical built environment. By combining the regulations on the cultural relics conservation with the national policy: ecological restoration and urban repair, a comprehensive conservation strategy was proposed under the guidance of the spatial prototype and evaluation results. First of all, the primary and basic work is to restore and utilize the three historical blocks. Then, around the historical block, there are several areas with high renewal potential, which may be considered as redevelopment objects in the near future, they should play an important role in building 
height and style to coordinate historical blocks and modern blocks. Next, on the basis of integrating landscape images from different directions, renovate the historical axis-streets and moat to enhance the integrity of the North-South historical trade pattern and the connection between the East and the West Hills. In addition, for those historical spatial elements with low resolution, it is necessary to show their historical and cultural information in the way of landscape. Therefore, conservation and construction work can be coordinated and differentiated in the dimension of prototype, and for the area with little connection to the prototype pattern, the control requirements can be relaxed to adapt to urban development (Figure 7).

\section{Conclusion}

The non-holistic problem of new and old space elements intermingled in urban historical built environment is becoming a common phenomenon in China. Traditional conservation methods which mainly focused on outstanding historical buildings are difficult to adapt to the current situation. By combining historical areas with the potential renewal plots, this paper explored an approach to evaluate the existing value of historic urban area based on the spatial prototype and put forward a constructive conservation strategy, not just simple control and repair in the past. It is helpful to unify heritage conservation and socio-economic development.

Then, evaluated the current situation of Jingmen historic urban area from three aspects: the resolution of historical elements, the integrity of historical structure and the renewal potential of related land, and found that the value of the historical built environment lied in the historical axis-street network and the overall connection between the ancient city's images in different directions. Therefore, based on the holistic pattern of spatial prototype, an adaptive strategy of coordinating ancient and new elements to enhance the integrity of the historic urban area was suggested.

Finally, it is important to note that the evaluation method in this paper, in some sense, is based on the characteristics of Jingmen historic urban area. However, different cities may show different characteristics, and it is necessary to optimize and apply the method flexibly in certain circumstances.

\section{Acknowledgements}

First of all, we would like to extend our sincere gratitude to Yang kai and Fan qing, section chiefs of Jingmen Urban and Rural Planning Bureau, for their help in the field and questionnaire survey. We are also deeply indebted to Prof. Chen Jinfu, Dr. Wang Zhenyu and other invitees for their help and advice in the process of determining the scores and weighting coefficients of Physical visibility.

\section{References}

Dong, W. 'Returning to the historical structure of urban-rural integration: constructing a holistic cultural landscape system in Pingyao', Design Community, 2019(02), p8-18.

Lin, L. 'Conservation of historic and culture cities in the context of the new normal: perspective of historic urban area', Urban Planning Forum, 2016(04), p94-101.

$\mathrm{He}, \mathrm{Y}$. 'Towards the "Post-Historic and Cultural City Era": exploring the systematic construction of historic urban areas', Heritage Architecture, 2017(03), p24-33.

Yang, J.Y. 'The prototypical "Four-stage" spatial structure and successional mechanism of asian urban central districts', Urban Planning Forum, 2016(02), p18-27. 
Chang, Q. 'On inheritance of built heritage in modern architectural context: theory and practice based on prototypal analysis', Bulletin of Chinese Academy of Sciences, 32(07), p667-680.

Zhang, L.H. 'While thousands and thousands transforms going on the spirit will last forever: analysis of the topological transformation of historical archetype', China Architectural Education, 2016 (04), p104-115.

Huang, S.J. (trans.) (2006) The Architecture of the City. 1st edn. Beijing: China Architecture \& Building Press.

Liu, L. 'Protection and development strategy of traditional village based on prototype identification: a case study of west river dawan village in Xin town in south of Henan area', Modern Urban Research, 2017(09), p48-54+84.

Wang, L.J. (2019) Typology of architecture. 3rd edn. Beijing: China Architecture \& Building Press.

Zhu, W.Y. (2011) Space, symbol and city: a theory of urban design. 2nd edn. Beijing: China Architecture \& Building Press.

Shen, K.L. (2010) Architectural typology and urban morphology. 1st edn. Beijing: China Architecture \& Building Press.

Wang, L.J. (2019) Typology of architecture. 3rd edn. Beijing: China Architecture \& Building Press.

Shen, K.L. (2010) Architectural typology and urban morphology. 1st edn. Beijing: China Architecture \& Building Press.

Yang, Z.T. (1994) A study of post stations in Ming dynasty. 1st edn. Shanghai: Shanghai Classics Publishing House.

Lu, X.Q. (2011) Inside and outside the wall: the form and spatial structure of the cities in the ancient Han river basin. 1st edn. Beijing: Zhong Hua Book Company.

Li, B.W., Wang, W. and Li, W.H. (2011) Interpretation and utilization of ten cultural brands in Jingmen: Jing-Xiang ancient road. 1st edn. Wuhan: Hubei People's Press.

$\mathrm{Xu}, \mathrm{G} . T$. 'The non-holistic problem and responsive integrated countermeasures of historic and cultural villages: an enlightenment from the planning practice in Ningbo', Architectural Journal, 2020(02), p9-15. 